Timmers, L., Thong, M., Dekker, F.W., Boeschoten, E.W., Heijmans, M., Rijken, M., Weinman, J Kaptein, A. Illness perceptions in dialysis patients and their association with quality of life.

\begin{tabular}{|l|l|}
\hline Postprint Version & 1.0 \\
\hline Journal website & $\underline{\text { http://www.informaworld.com/smpp/content } \sim \mathrm{db}=\text { all?content=10.1080/1476832 }}$ \\
\hline Pubmed link & $\underline{0701246535}$ \\
\hline DOI & $10.1080 / 14768320701246535$ \\
\hline
\end{tabular}

This is a NIVEL certified Post Print, more info at http://www.nivel.eu

\title{
Illness perceptions in dialysis patients and their association with quality of life
}

LUCIE TIMMERS $^{\text {A }}$; MELISSA THONG ${ }^{\text {B }}$; FRIEDO W. DEKKER ${ }^{\text {B }}$; ELISABETH W. BOESCHOTEN $^{\mathrm{C}}$; MONIQUE HEIJMANS ${ }^{\mathrm{D}}$; MIEKE RIJKEN ${ }^{\mathrm{D}}$; JOHN WEINMAN ${ }^{\mathrm{E}}$; AD KAPTEIN FOR THE NETHERLANDS COOPERATIVE STUDY ON THE ADEQUACY OF DIALYSIS (NECOSAD) STUDY GROUP ${ }^{\text {A }}$

1Unit of Psychology, Leiden University Medical Centre (LUMC), 2300 RB Leiden, The Netherlands,

2Department of Clinical Epidemiology, Leiden University Medical Centre, Leiden, The Netherlands,

3Hans Mak Institute, Naarden, The Netherlands,

4NIVEL, Netherlands Institute for Health Services Research, Utrecht, The Netherlands, and 5 Health Psychology Section, Department of Psychology (at Guy's), Institute of Psychiatry, London, UK

\begin{abstract}
The present study explored illness perceptions of end stage renal disease (ESRD) patients on both haemodialysis (HD) and peritoneal dialysis (PD) treatment, and their associations with quality of life. Leventhal's self-regulation model (SRM) was used as a theoretical framework. Illness perceptions and quality of life were assessed with the IPQ-R and the SF-36 in 91 HD and 42 PD patients participating in the NECOSAD-study. Compared to HD patients, PD patients experienced more personal control and had a better understanding of the illness. Illness perceptions explained from 17 to $51 \%$ of the variance in quality of life scores. Perception of more symptoms, more consequences and lower personal control were associated with lower well-being. The concept of illness perceptions is useful in understanding the impact of ESRD and of dialysis treatment on quality of life. Interventions aimed at providing more knowledge about ESRD and dialysis, and provision of skills to coping with the illness and its consequences may improve quality of life in dialysis patients.
\end{abstract}

\section{INTRODUCTION}

Dialysis is an artificial way of filtering the blood. It is a necessary treatment for patients diagnosed with End Stage Renal Disease (ESRD) unless kidney transplantation is available (Gokal \& Nolph, 1994). In ESRD, kidney function has decreased to $10-15 \%$ of its original functioning which is life-threatening without treatment. There are two dialysis modalities. In haemodialysis (HD) the blood is purified by an external artificial kidney. In peritoneal dialysis (PD) the peritoneal membrane functions as an artificial kidney (Cameron, 1996). 
Timmers, L., Thong, M., Dekker, F.W., Boeschoten, E.W., Heijmans, M., Rijken, M., Weinman, J Kaptein, A. Illness perceptions in dialysis patients and their association with quality of life.

Psychology \& Health: 2008, 23(6), 679-690

Dialysis patients may be faced with serious stressors related to the illness and its treatment, arising from the chronic nature of ESRD and the intrusiveness of the medical treatment. Patients are often confronted with limitations in food and fluid intake; with physical symptoms such as itching and lack of energy; with psychological stressors such as loss of self-concept and self-esteem, feelings of uncertainty about the future, and feelings of guilt towards family members; and with problems in the social domain (Cameron, 1996; Christensen, \& Ehlers, 2002; Covic, Seica, Gusbeth-Tatomir, Gavrilovici, \& Goldsmith, 2004; Krespi, Bone, Ahmad, Worthington, \& Salmon, 2004).

When confronted with an illness, people create their own models and representations of the illness in order to make sense of, and respond to, the problems they are faced with. Leventhal's Self-Regulation Model (SRM) provides a theoretical framework for the concept of illness cognitions (also called illness perceptions or illness representations) in relation to coping behaviours and outcome such as (adaptive) functioning and well-being (Cameron \& Leventhal, 2003; Cameron \& Moss-Morris, 2004; Caress, Luker, \& Glynn Owens, 2001; Hagger \& Orbell, 2003; Heijmans \& De Ridder, 1998; Rees, Fry, Cull, \& Sutton, 2004). Leventhal's model has been tested in many studies involving a range of chronic physical illnesses including chronic fatigue syndrome, multiple sclerosis, rheumatoid arthritis, chronic obstructive pulmonary disease, psoriasis, Huntington's disease, breast cancer, myocardial infarction and venous thrombosis (Kaptein et al., 2003). These studies indicate that when patients have more positive beliefs in the controllability and curability of the illness, this positively influences well-being (Hagger \& Orbell, 2003). Despite the demonstrated support for the SRM, questions have arisen about the mediating role of coping (Kaptein et al., 2006; Moss-Morris, Petrie, \& Weinman, 1996; Scharloo et al., 1998, 2005). The findings suggest that by identifying patients' beliefs about an illness and its treatment, it might be possible to obtain more insight into the (mal-) adaptive responses to the illness. Subsequently, this can provide a basis for developing interventions aimed at altering patients' perceptions to improve adaptive functioning. Petrie, Cameron, Ellis, Buick and Weinman (2002) observed that patients with myocardial infarction (MI) demonstrated better functional outcomes after MI following an individualized in-hospital intervention designed to change patients' illness perceptions.

The enormous impact of dialysis on quality of life has been emphasized in many studies (Caress et al., 2001; Christensen \& Ehlers, 2002; Covic et al., 2004; Fowler \& Baas, 2006; Korevaar et al., 2002; Krespi et al., 2004; Merkus et al., 1999; Vázquez et al., 2005). From these studies it is known that quality of life in dialysis patients is dramatically lower than that of the general population. HD and PD patients differ in age (HD patients are older) but also in perceived well-being: the physical quality of life over time is better in HD patients compared to PD patients. Less is known about the illness perceptions of dialysis patients or about the relationship between illness perceptions and health related quality of life in this patient group. A detailed electronic search strategy on this subject (in PubMed, PsychInfo, EMBASE, Cochrane and Web of Science, publications up till May 2006) demonstrated that the available research is concentrated mainly on HD patients. The results suggest that beliefs in controllability and consequences are key factors in these patients. More control and perception of fewer consequences is associated with a better outcome (Covic et al., 2004; Fowler, \& Baas, 2006; Krespi et al., 2004; Pucheu, Consoli, D'Auzac, Fraņais, \& Issad, 2004). Christensen and Ehlers (2002) outline how perceived control in these patients affects levels of depression, and morbidity and mortality.

The aims of the present study were to investigate the illness perceptions of HD and PD patients, and to examine the relationship between these perceptions and quality of life. The SRM served as the theoretical model. The following research questions were formulated: (1) What are the differences in illness perceptions between HD and PD patients? and (2) What is the effect of illness perceptions on health related quality of life after controlling for demographic and clinical variables? We hypothesized that there would not be a significant difference in illness perceptions between HD and PD patients. Further, based on the 
Timmers, L., Thong, M., Dekker, F.W., Boeschoten, E.W., Heijmans, M., Rijken, M., Weinman, J Kaptein, A. Illness perceptions in dialysis patients and their association with quality of life.

Psychology \& Health: 2008, 23(6), 679-690

literature on illness perceptions in other chronic illnesses, we expected to find a negative association between a strong illness identity, serious consequences, a chronic timeline and physical functioning. High perception of control was expected to have a positive association with physical and mental functioning.

\section{METHOD}

\section{Participants and procedure}

The Netherlands Cooperative Study on the Adequacy of Dialysis (NECOSAD-2) is a large multi-centre longitudinal research (38 dialysis centres and hospitals in the Netherlands) analysing the factors that contribute to the effect of dialysis treatment (both HD and PD) (see Merkus et al., 1999, for details). The NECOSAD-2 study was approved by the Medical Ethical Committees of the participating centres and hospitals. The inclusion criteria were: being over 18 years old, and having no previous history of renal replacement therapy. Patients gave their informed consent before being included. Between 1997 and 2004, 2000 patients were recruited. Clinical and quality of life data were collected every 6 months. Quality of life data were collected with questionnaires that patients filled in at home and returned by mail. Since October 2004, the Illness Perception Questionnaire revised (IPQ-R) has been added to the quality of life assessment. For the present study those patients were included for whom demographic, clinical, quality of life and baseline IPQ-R scores were available in the period from October 2004 up to and including March 2005. This consisted of 133 patients. This sample represents a selection from the patients that survived $(n=438)$ since the inception of the cohort. The mailing wave that included the IPQ-R encompassed 167 patients. Response rate, therefore, is 79.6\% (133 : 167). All questionnaires were in Dutch.

\section{Measures}

The IPQ-R is a frequently applied instrument developed to assess the dimensions as proposed by the SRM (originally developed as the IPQ by Weinman, Petrie, Moss-Morris and Horne (1996); in 2002 revised by Moss-Morris et al., 2002). One of the advantages of the IPQ- $\mathrm{R}$ is that it can be adapted to (patient) groups by adding to or adjusting the scales (Moss-Morris et al., 2002; Weinman et al., 1996). It is a widely used measure in patients with chronic illnesses, including psychiatric illnesses (Lobban \& Barrowclough, 2005), and has also been used with non-patient groups (Weinman, Petrie, Sharpe, \& Walker, 2000). The psychometric properties of the IPQ-R have been proven to be sound. For details on the scoring of the IPQ-R we refer to Moss-Morris et al., 2002.

Health related quality of life was measured with the 36-item Short Form Health Survey Questionnaire (SF-36 ${ }^{\mathrm{TM}}$ ) (Ware \& Sherbourne, 1992). This self report instrument is a reliable and valid instrument. It has been extensively used in many (patient) groups, including ESRD and dialysis patients (Knight, Ofsthun, Teng, Lazarus, \& Curhan, 2003; Korevaar et al., 2002; Lowrie, Curtin, Lepain, \& Schatell, 2003; Vázquez et al., 2005). The relevance of the SF-36 is demonstrated in studies in which it was used as a screening tool for dialysis patients to predict the risk of mortality and morbidity (Lowrie et al., 2003; Merkus et al., 1999).

Demographic and clinical data that were collected included age, gender, marital status, educational level, dialysis duration (in years), remaining renal function (residual glomerular filtration rate (rGFR)) and underlying kidney disease (Table I). Research has demonstrated the influence of rGFR on both survival and quality of life (Temorshuizen et al., 2003). Primary kidney disease is taken into account to correct for possible influences of the underlying disease on illness perceptions. 
Timmers, L., Thong, M., Dekker, F.W., Boeschoten, E.W., Heijmans, M., Rijken, M., Weinman, J Kaptein, A. Illness perceptions in dialysis patients and their association with quality of life.

Psychology \& Health: 2008, 23(6), 679-690

\section{[TABLE I]}

\section{Statistical analysis}

Differences between demographic and clinical characteristics, IPQ-R scores and SF-36 scores between the two groups (HD and PD patients) were compared by use of (non-) parametric tests (Student's $t$-test and chi-square). A factor analysis was performed on the IPQ-R causal items in order to gain insight into possible underlying dimensions for the two patient groups. To examine how much of the variance of each SF-36 scales could be explained by the illness perceptions, hierarchical multiple regression analyses were performed. In all analyses the first two steps included the entering of demographic and clinical variables in the equation to correct for possible confounding by these variables, and illness perception dimensions were entered at the third step. All analyses were performed with the Statistical Package for the Social Sciences (SPSS 12.0 for Windows).

\section{RESULTS}

\section{Sample characteristics}

From October 2004 to March 2005, the data of 133 patients were collected. Table I outlines the baseline characteristics of this patient group, divided into HD and PD.

\section{Illness perceptions}

Table II shows the scores on the IPQ-R subscales for both patients groups. PD patients experienced a higher level of personal control and had significantly higher scores on illness coherence compared with HD patients. The internal reliability of the different scales could be considered sufficient to be good with the exception of the treatment control scale ( $\alpha=$ 0.30). Therefore, treatment control was not included in further analyses.

\section{[TABLE II]}

With regard to the causal items, HD patients were significantly more inclined to attribute their illness to their emotional state, to their own behaviour, their own mental attitude and to smoking in comparison with PD patients $(t(116)=3.16, p<0.01$; $t(121)=2.15, p<0.05$; $t(123)=2.59, p<0.05 ; t(100)=2.37, p<0.05$, respectively). PD patients had stronger beliefs in hereditary causes for the illness $(t(125)=-2.54, p<0.05)$. It was not possible to identify clear causal factors for this sample by means of a principal component analysis.

\section{QUALITY OF LIFE}

Figure 1 presents mean scores on the SF-36 scales of the HD and PD patients compared to those of a non-clinical sample group in the same age-range (general population) as described by Ware and Sherbourne (1992). The dialysis patients in this study generally reported a lower quality of life compared to the general population. Exceptions were found on mental health, bodily pain and the mental component scores where the scores of PD patients were comparable to those of the general population. PD patients reported a better quality of life compared to HD patients. Significant differences between the two groups were found on the physical and social functioning scales, role functioning due to both physical and emotional problems, mental health, vitality and on the mental component score (MCS). 
Timmers, L., Thong, M., Dekker, F.W., Boeschoten, E.W., Heijmans, M., Rijken, M., Weinman, J Kaptein, A. Illness perceptions in dialysis patients and their association with quality of life.

Psychology \& Health: 2008, 23(6), 679-690

\section{[FIGURE 1]}

\section{ILLNESS PERCEPTIONS AND QUALITY OF LIFE}

To obtain a larger sample size on the basis of which more convincing conclusions could be drawn, the hierarchical regression analyses were performed on the total group of 133 patients.

From Table III, it can be concluded that demographic variables accounted for between 9 and $23 \%$ of the variance in physical functioning, social functioning, role functioning physical, role functioning emotional, mental health, bodily pain and the physical component score. The clinical variables that were entered in step 2 did not account for any variance in the outcome variables. The variable rGFR only demonstrated small beta weight significance on the physical component score. After controlling for both demographic and clinical variables, illness perceptions significantly explained variance in all of the outcome areas with a minimum of $17 \%$ for both role functioning emotional and bodily pain, and up to $51 \%$ of the mental health subscale. Each of the outcomes was explained by a different set of the illness perception subscales.

Illness identity showed significant negative contributions to most outcome areas.

Consequences and emotional representations, however, were more strongly associated with some of the outcome measures. Timeline acute/chronic was the only illness perception subscale that did not contribute to any of the outcome variables. Limited role functioning due to emotional problems was the only scale that was negatively associated with cyclical timeline beliefs. Personal control was significantly and positively related to physical and social functioning, bodily pain, general health perception and the physical component score. Illness coherence explained some of the variability in social functioning, mental health and the mental component score.

\section{DISCUSSION}

Leventhal's SRM was used in this study to examine the cognitive and emotional representations that a group of dialysis patients held about their illness and how these representations may be related to quality of life (Cameron \& Leventhal, 2003). The results of the present study support the strength and usefulness of the SRM and are consistent with findings of other studies about illness representations in patients with chronic illness, as described in a meta-analysis by Hagger and Orbell (2003). Contrary to our hypothesis, we found differences in illness perceptions between HD and PD patients in terms of reported personal control, illness coherence and possible causes for their ESRD. In the context of the self-regulation theoretical model, this is an important finding: our study is the first in an SRM-context that allows comparison of HD with PD patients on cognitive representations of their renal disease. PD patients are responsible for carrying out the dialysis treatment themselves, which not only requires knowledge about the actions (health behaviour) to be performed but also a set of cognitive representations that is instrumental in performing that health behaviour and maintaining psychological equilibrium. In this context, our study has produced highly relevant knowledge that supports the theoretical basis of the interventions developed by Christensen and Ehlers (2002) and Tsay, Lee and Lee (2005), that are aimed at improving illness coherence and control in psychological intervention studies (see also Cvengros, Christensen, \& Lawton, 2004, 2005).

From the regression analyses it can be concluded that illness perceptions contribute significantly to aspects of quality of life in this patient group, after controlling for the influence of confounding variables. A strong illness identity, many negative consequences, and low personal control were found to be associated with a lower well-being. This finding is consistent with the data in the meta-analysis on associations between illness cognitions and outcome measures, such as quality of life (Hagger \& Orbell, 2003). Symptoms did not influence the cognitive representations of the patients, which is consistent with earlier 
Timmers, L., Thong, M., Dekker, F.W., Boeschoten, E.W., Heijmans, M., Rijken, M., Weinman, J Kaptein, A. Illness perceptions in dialysis patients and their association with quality of life. Psychology \& Health: 2008, 23(6), 679-690

research (e.g., Scharloo et al., 2005; Steed, Newman, \& Hardman, 1999). The composite Mental health score had the highest amount of variance explained by more illness symptoms, a lower level of understanding and a stronger emotional response to the illness. This also can be conceptualized as support for SRM theory, in that stronger emotional representations tend to be associate with worse outcomes (Cameron \& Moss-Morris, 2004; Fowler \& Baas, 2006; Weinman et al., 2000).

In the context of the four earlier studies carried out specifically on illness representations in ESRD-patients, our study not only reports on the largest sample but it also supports their findings pertaining to higher identity and higher control being associated with a better outcome, and more perceived consequences, higher emotional representations and less control being associated with worse outcomes (Covic et al. 2004; Fowler \& Baas, 2006; Krespi et al., 2004; Pucheu et al., 2004). The research by the group of Christensen supports these notions (Christensen, Moran, Wiebe, Ehlers, \& Lawton, 2002; Cvengros et al., 2004, 2005).

The results of the present study support the use of the SRM for identifying illness perceptions of patients with chronic illness and the relationship between these perceptions and outcome - in this study: quality of life. A few limitations of the study should be discussed. Due to the cross-sectional character it is not possible to make statements about causalities between illness perceptions and quality of life. One of the most commonly mentioned physical complaints of ESRD patients is itching. This symptom was not included in the IPQ-R version used in this study; therefore, inclusion of this item in the symptom list of the IPQ-R for this patient group is recommended in future research. Longitudinal designs with questionnaires that are better tailored to the illness category and its symptoms under study are called for.

Compared with the general population, the quality of life of dialysis patients in this study is dramatically low, especially for the physical aspects of functioning. This is sufficient reason to improve the care for this patient group, not only medically but also psychologically. Tsay et al. (2005) showed that it is possible to improve adaptive functioning in HD patients by means of group interventions such as patient education and techniques to increase the patients' feelings of mastery and competence. The present study also demonstrated the influence of illness perceptions on perceived quality of life of dialysis patients. This suggests potential for investigating whether individually based or group-based interventions that are aimed at specific, inaccurate, individual illness perceptions can improve perceived quality of life in dialysis patients. Christensen et al. (2002) reported on the effects of a behavioural selfregulation intervention for adherence in patients on haemodialysis. In small groups patients discussed a self-regulation protocol with (psychologists) trainers. Adherence with fluid restrictions, a major self-regulatory task in these patients, was the target behaviour. The results are encouraging and form a further basis for developing and examining the effects of self-regulatory-based interventions in patients with haemodialysis and peritoneal dialysis.

\section{REFERENCES}

1. Cameron, S. (1996) Kidney failure Oxford University Press, New York

2. Cameron, LD and Leventhal, H. (2003) The self-regulation of health and illness behaviour Routledge, London, UK

3. Cameron, LD and Moss-Morris, R. Kaptein, A. and Weinman, J. (eds) (2004) Illnessrelated cognition and behaviour. Health psychology pp. 84-110. Blackwell Publishers \& British Psychological Society , Oxford

4. Caress, A., Luker, KA and Glynn Owens, R (2001) A descriptive study of meaning of illness in chronic renal disease. Journal of Advanced Nursing 33 , pp. 716-727.

5. Christensen, AJ and Ehlers, SL (2002) Psychological factors in end-stage renal disease: An emerging context for behavioral medicine research. Journal of Consulting and Clinical Psychology 70 , pp. 712-724. 
Timmers, L., Thong, M., Dekker, F.W., Boeschoten, E.W., Heijmans, M., Rijken, M., Weinman, J Kaptein, A. Illness perceptions in dialysis patients and their association with quality of life.

Psychology \& Health: 2008, 23(6), 679-690

6. Christensen, AJ, Moran, PJ, Wiebe, JS, Ehlers, SL and Lawton, WJ (2002) Effect of a behavioral self-regulation intervention on patient adherence in hemodialysis. Health Psychology 21 , pp. 393-397.

7. Covic, A., Seica, A., Gusbeth-Tatomir, P., Gavrilovici, O. and Goldsmith, DJA (2004) Illness representations and quality of life scores in haemodialysis patients. Nephrology, Dialysis and Transplantation 19 , pp. 2078-2083.

8. Cvengros, JA, Christensen, AJ and Lawton, WJ (2004) The role of perceived control and preference for control in adherence to a chronic medical regimen. Annals of Behavioral Medicine 27 , pp. 155-161.

9. Cvengros, JA, Christensen, AJ and Lawton, WJ (2005) Health locus of control and depression in chronic kidney disease: A dynamic perspective. Journal of Health Psychology 10 , pp. 677-686.

10. Fowler, C. and Baas, LS (2006) Illness representations in patients with chronic kidney disease on maintenance hemodialysis. Nephrology Nursing Journal 33 , pp. 173-186.

11. Gokal, R. and Nolph, KD (1994) The textbook of peritoneal dialysis Kluwer, Dordrecht

12. Hagger, MS and Orbell, S. (2003) A meta-analytic review of the common-sense model of illness representations. Psychology and Health 18 , pp. 141-184.

13. Heijmans, M. and De Ridder, D. (1998) Assessing illness representations of chronic illness: Explorations of their disease-specific nature. Journal of Behavioral Medicine 21 , pp. 485-503.

14. Kaptein, AA, Scharloo, M., Helder, DI, Kleijn, W., Chr, van Korlaar, IM and Woertman, M. Cameron, LD and Leventhal, H. (eds) (2003) Representations of chronic illnesses. The self-regulation of health and illness behaviour pp. 97-118. Routledge , London, UK

15. Kaptein, AA, Helder, DI, Scharloo, M., Van Kempen, GMJ, Weinman, J. Van Houwelingen, JC et al. (2006) Illness perceptions and coping explain well-being in patients with Huntington's disease. Psychology and Health 21 , pp. 431-446.

16. Knight, EL, Ofsthun, N., Teng, M., Lazarus, JM and Curhan, GC (2003) The association between mental health, physical function, and haemodialysis mortality. Kidney International 63 , pp. 1843-1851.

17. Korevaar, JC, Merkus, MP, Jansen, MAM, Dekker, FW, Boeschoten, EW and Krediet, RT (2002) Validation of the KDQOL-SF ${ }^{\mathrm{TM}}$ : A dialysis-targeted measure.. Quality of Life Research 11 , pp. 437-447. - for the NECOSAD-study group

18. Krespi, R., Bone, M., Ahmad, R., Worthington, B. and Salmon, P. (2004)

Haemodialysis patients' beliefs about renal failure and its treatment. Patient Education and Counseling 53 , pp. 189-196.

19. Lobban, F. and Barrowclough, C. (2005) Common sense representations of schizophrenia in patients and their relatives. Clinical Psychology and Psychotherapy 12 , pp. 134-141.

20. Lowrie, EG, Curtin, RB, Lepain, N. and Schatell, D. (2003) Medical outcomes study short form-36: A consistent and powerful predictor of morbidity and mortality in dialysis patients. American Journal of Kidney Diseases 41 , pp. 1286-1292.

21. Merkus, MP, Jager, KJ, Dekker, FW, De Haan, RJ, Boeschoten, EW and Krediet, RT (1999) Quality of life over time in dialysis: The Netherlands cooperative study on the adequacy of dialysis. Kidney International 56 , pp. 720-728.

22. Moss-Morris, R., Petrie, KJ and Weinman, J. (1996) Functioning in chronic fatigue syndrome: Do illness perceptions play a regulatory role?. British Journal of Health Psychology 1 , pp. 15-25.

23. Moss-Morris, R., Weinman, J., Petrie, KJ, Horne, R., Cameron, LD and Buick, D. (2002) The revised Illness Perception Questionnaire (IPQ-R). Psychology and Health 17 , pp. 1-16.

24. Petrie, KJ, Cameron, LD, Ellis, CJ, Buick, D. and Weinman, J. (2002) Changing illness perceptions after myocardial infarction: An early intervention randomised controlled trial. Psychosomatic Medicine 64 , pp. 580-586.

25. Pucheu, S., Consoli, SM, D'Auzac, C., Fraņ̧ais, P. and Issad, B. (2004) Do health causal attributions and coping strategies act as moderators of quality of life in peritoneal dialysis patients?. Journal of Psychosomatic Research 56 , pp. 317-322.

26. Rees, G., Fry, A., Cull, A. and Sutton, S. (2004) Illness perceptions and distress in women at increased risk of breast cancer. Psychology and Health 19 , pp. 749-765. 
Timmers, L., Thong, M., Dekker, F.W., Boeschoten, E.W., Heijmans, M., Rijken, M., Weinman, J Kaptein, A. Illness perceptions in dialysis patients and their association with quality of life.

Psychology \& Health: 2008, 23(6), 679-690

27. Scharloo, M., Kaptein, AA, Weinman, J., Hazes, JM, Willems, LNA, Bergman, W. and Rooijmans, HGM (1998) Illness perceptions, coping and functioning in patients with rheumatoid arthritis, chronic obstructive pulmonary disease and psoriasis. Journal of Psychosomatic Research 44 , pp. 573-585.

28. Scharloo, M., Baatenburg de Jong, RJ, Langeveld, TPM, Velzen-Verkaik, E. van, Doorn-op den Akker, MM and Kaptein, AA (2005) Quality of life and illness perceptions in patients with recently diagnosed head and neck cancer. Head \& Neck 27 , pp. 857-863.

29. Steed, L., Newman, SP and Hardman, SMC (1999) An examination of the selfregulation model in atrial fibrillation. British Journal of Health Psychology 4 , pp. 337-347.

30. Temorshuizen, F., Korevaar, JC, Dekker, FW, Van Manen, JG, Boeschoten, EW and Krediet, RT (2003) The relative importance of residual renal function compared with peritoneal clearance for patient survival and quality of life. An analysis of The Netherlands Cooperative Study on the Adequacy of Dialysis (NECOSAD-2).. American Journal of Kidney Disease 41 , pp. 1295-1302. - for the NECOSAD Study Group

31. Tsay, S-L, Lee, Y-C and Lee, Y-C (2005) Effects of an adaptation training programme for patients with end-stage renal disease. Journal of Advanced Nursing 50, pp. 39-46.

32. Vázquez, I., Valderrábano, F., Fort, J., Jofré, R., López-Gómez, JM Moreno, F. et al. (2005) Psychosocial factors and health-related quality of life in haemodialysis patients. Quality of Life Research 14 , pp. 179-190.

33. Ware, JE and Sherbourne, CD (1992) The MOS 36-item short form health survey (SF36): Conceptual framework and item selection. Medical Care 30 , pp. 473-483.

34. Weinman, J., Petrie, KJ, Moss-Morris, R. and Horne, R. (1996) The Illness Perception questionnaire: A new method for assessing the cognitive representation of illness.

Psychology and Health 11 , pp. 431-445.

35. Weinman, J., Petrie, KJ, Sharpe, N. and Walker, S. (2000) Causal attributions in patients and spouses following first-time myocardial infarction and subsequent lifestyle changes. British Journal of Health Psychology 5 , pp. 263-273.

\section{TABLES AND FIGURES}

Table I. Demographic and clinical characteristics.

\begin{tabular}{|c|c|c|}
\hline & $\mathrm{HD}$ & $\mathrm{PD}$ \\
\hline Number of patients (\%) & $91(68.4)$ & $42(31.6)$ \\
\hline Mean age in years $(\mathrm{SD})^{\star}$ & $68.46(11.36)$ & $63.02(11.77)$ \\
\hline Gender $(\% \text { male })^{\star \star}$ & $51(56.04)$ & $30(71.43)$ \\
\hline Mean years on dialysis $(\mathrm{SD})^{\star \star}$ & $4.28(1.73)$ & $3.33(1.59)$ \\
\hline Married/living together $(\%)^{\star \star}$ & $60(61.93)$ & $37(88.09)$ \\
\hline \multicolumn{3}{|l|}{ Education $^{\mathrm{a}}(\%)^{\star \star \star}$} \\
\hline Primary & $46(50.48)$ & $16(38.08)$ \\
\hline Secondary & $33(36.27)$ & $18(42.87)$ \\
\hline Tertiary & $8(8.80)$ & $7(16.63)$ \\
\hline Unknown & $4(4.45)$ & $1(2.42)$ \\
\hline $\operatorname{rGFR}(\mathrm{SD})^{\mathrm{b}}$ & $3.37(3.81)$ & $3.81(2.74)$ \\
\hline \multicolumn{3}{|l|}{ Primary kidney disease $(\%)^{\star \star \star}$} \\
\hline Diabetes mellitus & $9(9.90)$ & $3(7.15)$ \\
\hline Glomerulonephritis & $6(6.60)$ & $6(14.28)$ \\
\hline Vascular cause & $15(16.48)$ & $5(11.90)$ \\
\hline Other/unknown & $61(67.02)$ & $28(66.67)$ \\
\hline
\end{tabular}

Note: HD: Haemodialysis; PD: peritoneal dialysis.

${ }^{a}$ Primary: primary school and lower vocational education; secondary: secondary school for lower; intermediate vocational education, general education, general secondary education and pre-university education; tertiary: higher professional education and university.

rGFR: residual glomerular filtration rate (individuals with an rGFR below 60 are classified as having chronic kidney disease, normal values range between 118 and 127 for young, healthy people).

${ }^{\star} p<0.05 ;{ }^{\star \star} p<0.01 ;{ }^{\star \star \star} p<0.001$. 
Timmers, L., Thong, M., Dekker, F.W., Boeschoten, E.W., Heijmans, M., Rijken, M., Weinman, J Kaptein, A. Illness perceptions in dialysis patients and their association with quality of life.

Psychology \& Health: 2008, 23(6), 679-690

Table II. Differences in scores on the IPQ-R scales between HD and PD patients.

\begin{tabular}{lcccrr}
\hline Dimension & $\begin{array}{c}\text { Number of } \\
\text { items }(N)\end{array}$ & $\begin{array}{c}\text { Min/max } \\
\text { score }\end{array}$ & $\begin{array}{c}\text { HD } \\
(M, \text { SD })\end{array}$ & $\begin{array}{c}\text { PD } \\
(M, S D)\end{array}$ & $t$-value (df) \\
\hline $\begin{array}{l}\text { Illness identity }(\alpha=0.77) \\
\text { Timeline acute/chronic }\end{array}$ & 14 & $0-14$ & $5.11(3.06)$ & $4.59(3.25)$ & $0.88(131)$ \\
$\quad(\alpha=0.82)$ & 6 & $6-30$ & $25.16(4.31)$ & $26.10(4.69)$ & $-1.11(126)$ \\
Timeline cyclical $(\alpha=0.84)$ & 4 & $4-20$ & $11.91(3.82)$ & $11.51(4.15)$ & $0.51(113)$ \\
Consequences $(\alpha=0.65)$ & 6 & $6-30$ & $20.90(4.07)$ & $20.33(4.87)$ & $0.69(127)$ \\
Personal control $(\alpha=0.67)$ & 6 & $6-30$ & $16.34(3.71)$ & $18.95(4.22)$ & $-3.58(127)^{\star \star \star}$ \\
$\begin{array}{l}\text { Treatment control }(\alpha=0.30) \\
\text { Illness coherence }(\alpha=0.78)\end{array}$ & 5 & $5-25$ & $14.36(2.63)$ & $14.74(2.55)$ & $-0.78(127)$ \\
$\begin{array}{l}\text { Emotional representations } \\
\quad(\alpha=0.92)\end{array}$ & 5 & $5-25$ & $17.87(3.85)$ & $19.86(3.68)$ & $-2.78(127)^{\star \star}$ \\
& 6 & $6-30$ & $15.94(5.76)$ & $14.31(5.81)$ & $1.40(113)$
\end{tabular}

Note: $N$ varies in HD-group from 87 to $91 ; N$ varies in PD-group from 37 to 42 .

${ }^{\star \star} p<0.01 ;{ }^{\star \star \star} p<0.001$.

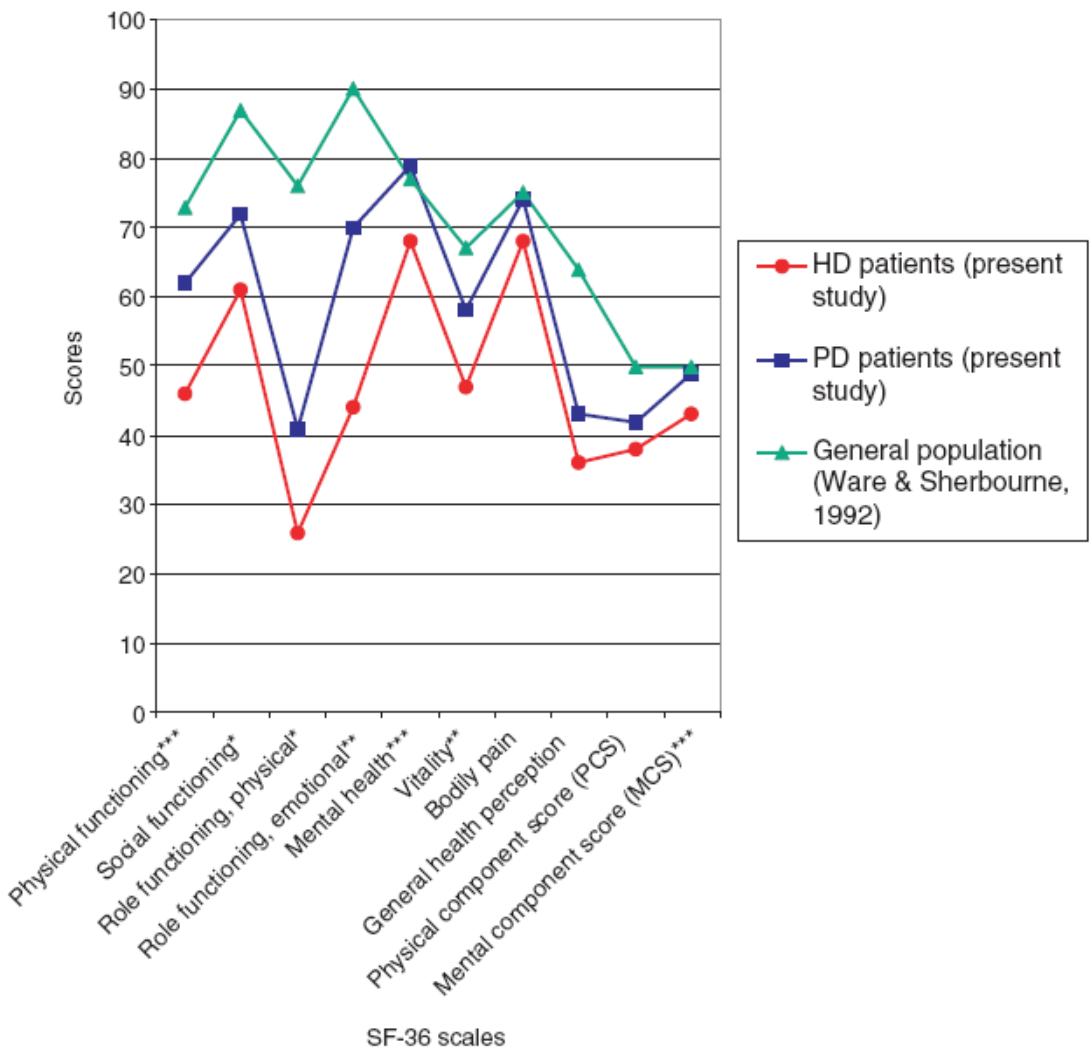

Figure 1. Differences in scores on the SF-36 scales between HD patients $(N=91)$, PD patients $(N=42)$ and the general population $\left(N=140\right.$; Ware \& Sherbourne, 1992). The asterisks $\left(^{\star}\right)$ demonstrate the significance of the performed $t$-tests between HD and PD patients.

Note. $N$ varies in $\mathrm{HD}$ group from 87 to 91 ; in PD group from 41 to 42 . ${ }^{\star} p<0.05$; ${ }^{\star \star} p<0.01$; $\star \star * x<0.001$. 